\title{
Study of Hematological Characteristics and Mineral Metabolism of Moscow Black Chickens in the Process of Acclimatization in the Astrakhan Region
}

\author{
Bratashova Tatyana Sergeevna ${ }^{1}$, Zakharkina Natalya Ivanovna ${ }^{1}$, Shcherbakova Elena Nikolaevna ${ }^{1}$, \\ Safonov Vladimir Aleksandrovich ${ }^{1}$, \\ ${ }^{1}$ Astrakhan State University, 20a Tatishcheva St., Astrakhan, 414056, Russia
}

Received: May 26, 2021. Revised: November 22, 2021. Accepted: December 7, 2021. Published: January 3, 2022.

\begin{abstract}
The study of indicators characterizing the processes associated with the acclimatization of birds in new biogeochemical conditions is of interest in connection with the prospects of the poultry industry in the Astrakhan Region, where the lack of important trace elements in soils and plant feeds: Se, I, Co, is observed. In the presented study, the main hematological and biochemical parameters of blood and mineral metabolism were determined in 2 groups of chickens of the Moscow black breed: imported to the Astrakhan Region from Moscow and kept in the Moscow Region. The analyses revealed strong differences $(P<0.01)$ in indicators of two groups. The acclimatized birds were characterized by low levels of red blood cells and hemoglobin in the blood, as well as a higher content of white blood cells than in the second group. The chickens had impaired lipid and protein metabolism. A 71.3\% increase in the level of total sugar most likely indicated a stress state of birds. Compared with the chickens in the Moscow Region, the level of calcium in their blood was $32.4 \%$ lower, phosphorus $-12.9 \%$. To a large extent, a decrease in the levels of iodine and selenium - by 5.3 and 5.2 times, respectively, was observed. Thus, in the absence of external changes, acclimatized chickens are subject to a latent form of combined I- and Se-hypomicroelementosis. At the same time, a drop in egg productivity by $19 \%$ is the recorded fact. The necessity to adapt to the new climatic conditions of the Lower Volga region for birds, combined with a lack of important trace elements, can cause increased oxidative stress in acclimatized birds. Based on the results of the study, the use of feed additives that make up for the deficiency of necessary trace elements is recommended.
\end{abstract}

Keywords - chickens, hematology, trace elements, hypomicroelementoses, acclimatization.

\section{INTRODUCTION}

DOULTRY farming is one of the most promising branches of livestock breeding, due to the rapid reproduction, high productivity indicators of modern breeds and crosses of poultry, high conversion of feed into live weight, and egg productivity. The result of long-term breeding work was a wide variety of chickens of different productivity directions. In farms and private farmsteads, the "Moscow black" breed has become quite widespread, since these chickens are distinguished by a combination of relative unpretentiousness to the breeding conditions with good levels of meat and egg productivity.

Birds are characterized by a high intensity of metabolic processes, and therefore are extremely sensitive to an insufficient level of trace elements. It is especially necessary to pay attention to a balanced intake of nutrients, vitamins, and mineral elements when organizing the feeding of poultry, that is, in the process of acclimatization in new conditions. The ratio of macronutrients in the diet has a strong influence on energy, protein, and lipid metabolism. Changes in the constitution of poultry, heat production, energy distribution between proteins and fats caused by feeding characteristics are reflected, including at the level of intermediate metabolites and hormones [1].

Currently, it is known that the biogeochemical conditions of the Lower Volga region are characterized by low levels of cobalt, iodine, and selenium in the soil and plant feeds. Over the years of observations of arable soils, the balance of the main nutrients in them was deeply negative and was not compensated by the applied fertilizers [2,3]. At the same time, the agrobiocenoses of the Astrakhan Region contain sufficient amounts of zinc, copper, and iron for chickens and other animals. In the studies devoted to the problems of the elemental composition of soils and plant feeds of the adjacent regions of Astrakhan, the following data are given on the gross levels of trace elements in soils: $\mathrm{Se}-0.24 \pm 0.004 \mathrm{mg} / \mathrm{kg}$, I $0.3 \pm 0.009 \mathrm{mg} / \mathrm{kg}, \mathrm{Co}-6.9 \pm 0.87 \mathrm{mg} / \mathrm{kg}[4,5]$. In the studied 
soil samples from different parts of the region, no cases of selenium surplus were recorded, and $19 \%$ of soils were characterized by a marginal deficiency of the trace element at the level of $0.125-0.175 \mathrm{mg} / \mathrm{kg}$ [6]. Plants and feed produced on their basis have a very low level of elements: $\mathrm{Se}-0.02$ $0.12 \mathrm{mg} / \mathrm{kg}$, I $-0.01-0.07 \mathrm{mg} / \mathrm{kg}$, Co $-0.01-6.00 \mathrm{mg} / \mathrm{kg}$. Iodine and selenium provide the physiological work of the thyroid gland, the hormones of which affect the metabolism of birds, growth functions, and productivity. These trace elements also provide control of the balance of lipid peroxidation and antioxidant protection, by reducing the degree of oxidative stress, and have an adaptogenic effect [7, 8]. Sufficient iodine supply to the parent herd is a necessary condition for the embryonic development and hatchability of chicks [9].

For economic benefit, farms practice raising animals on feeds produced in a poultry farm at their feed mill [10] or on feeds from local producers, the components of which are obtained in the same region that is insufficient for any elements. In conditions predisposing to the development of pathologies associated with a lack of trace elements in animals, it is important to timely diagnose hidden forms of hypomicroelementosis that occur without clinical symptoms but cause deterioration of productive characteristics [11, 12].

\section{RELEVANCE AND WORK OBJECTIVE}

The poultry industry is developing in the Lower Volga region, which is associated with the necessity to import promising species and breeds of chickens, guinea fowls, and quails. The effective organization of farms aimed at obtaining poultry products implies the successful adaptation of newly imported animals associated with stress due to changed conditions. To realize the productive potential, it becomes important to control the intake and metabolism of nutrients and elements in birds. The work objective was to study the main hematological and biochemical parameters of blood, including mineral metabolism, of Moscow black chickens imported to the farm of the Astrakhan Region, due to acclimatization in an environment poor in iodine and selenium. The study of blood composition for understanding adaptive processes and various aspects of animal health is a common and affordable diagnostic method [13]. The study of the adaptive processes of poultry in the Lower Volga region was started by the example of various breeds of pigeons, quails, and guinea fowls. This paper will be the first devoted to the blood parameters of Moscow black chickens in the process of acclimatization in the Astrakhan Region.

Taking into account the found lack of important trace elements in local agrobiocenoses and peculiarities of the continental arid climate, it can be assumed that some deviations of the studied indicators from those of chickens in the native region and reference values will be observed.

\section{MATERIALS AND METHODS}

The study subject was chickens of the Moscow black breed, kept in one of the farms of the Trusovsky District of the Astrakhan Region, where they were previously imported from the village Rusavkino-Romanovo, a city district of Balashikha, located in the Moscow Region. The comparison group consisted of chickens of the same breed, kept at a farm in the Moscow Region during the study. Each group of chickens included 15 individuals of 10 months of age. The birds' diet consisted of local feed ad lib.

For hematological analysis and determination of the concentration of trace elements, blood was taken from the wing vein after antiseptic treatment. Laboratory tests of blood samples were carried out following generally accepted methods, the results were processed using the Statistica 8.0 program with the expression of the results in the form of arithmetic mean and a standard error.

\section{RESULTS}

The known data on the levels of trace elements in the biogeocenoses of the Astrakhan Region give grounds to attribute the region to biogeochemical provinces that are deficient in iodine and selenium content, which leads to a change in the hematological characteristics of birds. It is important to mention that the acclimatized chickens had no clinical manifestations indicating deviations of physiological processes from the norm.

Table 1. Hematological indicators and indicators of mineral metabolism of Moscow black chickens in the conditions of the Astrakhan and Moscow Regions

\begin{tabular}{lcc}
\hline Indicators & $\begin{array}{c}\text { Astrakhan Region } \\
(\mathbf{N}=15)\end{array}$ & $\begin{array}{c}\text { Moscow Region } \\
(\mathbf{N = 1 5})\end{array}$ \\
\hline Red blood cells, & $2.89 \pm 0.06^{*}$ & $3.76 \pm 0.12$ \\
$10^{12} / 1$ & & \\
Hemoglobin, g/1 & $76 \pm 3.1^{*}$ & $115 \pm 1.12$ \\
White blood cells, & $32.0 \pm 1.1^{*}$ & $26.3 \pm 0 / 58$ \\
$10^{9} / 1$ & & \\
Total protein, g/l & $26.1 \pm 1.06^{*}$ & $37.1 \pm 2.06$ \\
Triglycerides, & $8.05 \pm 0.08^{*}$ & $14.05 \pm 0.03$ \\
mmol/1 & & \\
Uric acid, mg\% & $0.05 \pm 0.002^{*}$ & $0.08 \pm 0.001$ \\
Total sugar, mg/\% & $209 \pm 1.98^{*}$ & $122 \pm 2.2$ \\
Calcium, mg/l & $2.3 \pm 0.1^{*}$ & $3.4 \pm 0.3$ \\
Phosphorus, mg/1 & $1.48 \pm 0.05^{*}$ & $1.7 \pm 0.02$ \\
Iodine, mg/l & $0.51 \pm 0.03^{*}$ & $2.70 \pm 0.08$ \\
Selenium, mg/l & $0.025 \pm 0.002^{*}$ & $0.13 \pm 0.01$ \\
\hline
\end{tabular}

$*-\mathrm{P}<0.01$ relative to indicators of chickens from the Moscow Region.

The results of the study blood samples of 10-month-old chickens of Moscow black breed listed in Table 1 and Figure 1 show that during the acclimatization in terms of a biogeochemical province, birds have a reduced number of red blood cells in comparison with the results of the birds in the Moscow Region by $23.1 \%$. In addition, the indicator in birds of the Astrakhan Region is below 3.7\% of normal values for chickens of this age, given in the reference literature $[14,15]$ and amounting to $3-4 \cdot 10^{12} / 1$. The number of red blood cells above the average physiological level is typical for chickens of the Moscow Region. In addition, in birds of this group, a good 
blood saturation with hemoglobin is observed; its concentration tended to the upper limit of the norm of 80 $120 \mathrm{~g} / \mathrm{l}$. The hemoglobin level in birds of the Astrakhan Region is significantly lower - by $33.9 \%$ than in birds of the Moscow Region and by $5.0 \%$ below the minimum limit of reference indicators. Among the reasons for the decrease in the content of red blood cells and hemoglobin in chickens, insufficient nutrition and the impact of stress factors are the most possible.

The content of white blood cells in the blood in both groups was within the normal range of $20-40 \times 10^{9} / 1$; however, in the Astrakhan biogeochemical province, the number of white blood cells in chickens was closer to its maximum value, and also exceeded the number in birds from the Moscow Region by $21.7 \%$, which may indicate the mobilization of the immune system during acclimatization.

\section{Astrakhan region $\quad$ Moscow region}

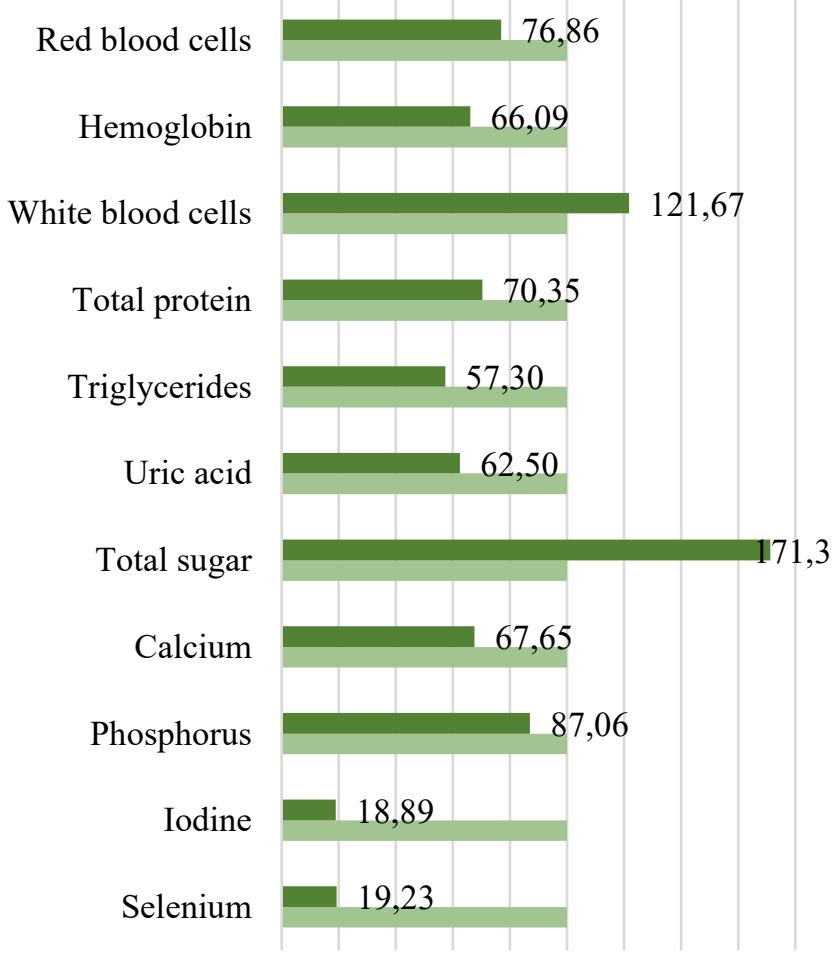

Figure 1. The percentage ratio of hematological characteristics of acclimatized chickens in the Astrakhan Region and chickens in native conditions of the Moscow Region (100\%)

The indicators of total protein in the blood of chickens of both groups are below the standard values (43-59 g/l). In chickens in the conditions of the Astrakhan Region, its level is $39.3 \%$ lower than the minimum border and $29.6 \%$ lower than in the group in the farm of the Moscow Region. Low indicators of total protein in the blood may indicate an insufficient intake of proteins from feed, or a large expenditure of proteins to maintain metabolic processes with inevitably occurring stress during adaptation to changed conditions. The state of protein metabolism is characterized by the content of its final metabolite in the blood - uric acid (the norm for chickens is $0.05-0.12 \mathrm{mg} \%$ ). In acclimatized birds, its concentration corresponded to the lower limit of the norm, it was also $37.5 \%$ lower than in chickens of the Moscow Region under unchanged conditions, i.e. protein metabolism is quite low, most likely due to a reduced intake of nutrients into the body.

The largest part of blood plasma lipids in birds is represented by triglycerides, the content of which in animals in the conditions of the Astrakhan Region is reduced by $42.7 \%$ in comparison with birds of the Moscow Region. Presumably, it is due to the increased catabolism of lipids in the new conditions amid the low level of their intake.

The level of total sugar in the range of $120-200 \mathrm{mg} \%$ is considered normal in Russian chickens. Thus, in Moscow black chickens of the Astrakhan Region, the concentration of total sugar is slightly higher than the upper limit of the physiological norm, and it is also $71.3 \%$ higher in the second group. An increase in sugar concentration in the blood of birds often indicates their stressful state.

Visualization of morphological and biochemical parameters of blood in Figure 1 shows strong changes in the metabolism of chickens under adaptation, which significantly affected all other indicators. The greatest relative differences are noticeable in the concentrations of trace elements.

Birds acclimatized in the biogeochemical province show a reduced supply of the necessary mineral elements. In comparison with the chickens of the Moscow Region, their calcium level is $32.4 \%$ lower, phosphorus $-12.9 \%$. The Ca:P ratio is 1.55 (should be higher than 1 with moderate productivity). The levels of iodine and selenium, which are critical for the health and productive qualities of poultry, were significantly reduced - by 5.3 and 5.2 times respectively. A decrease in the activity of antioxidant enzymes and the accumulation of lipid peroxidation products are associated with a lack of iodine and, especially, selenium. With the established combined hypoelementosis, no clinical signs were noted in acclimatized birds that could indicate a deficiency of the necessary elements; however, a comparison of the egglaying indicators of chickens showed a $19 \%$ reduced productivity in the conditions of the Astrakhan Region.

\section{DISCUSSION}

In the case of a deficiency of physiologically important trace elements in the environment and feeds, the resistance of the poultry body decreases, the development of feed stress is observed. In addition to the established latent form of combined hypoelementosis, it will be possible to assume the influence of the temperature and climatic factor on the process of poultry adaptation in new conditions. It is important to note that the region under consideration is characterized by a continental arid climate and a hot summer season, a gradual increase in average annual temperatures, the average sum of temperatures during the growing season, and a decrease in precipitation [16, 17]. It is well known that the ambient temperature strongly affects the condition of poultry. Studies confirm that the process of domestication and breeding has affected the resistance of chickens to the stressful effects of 
high temperatures in places of living negatively [18]. Stress due to high temperatures, which manifests itself when the usual optimal limits for the species and breed are exceeded, provokes changes in the metabolic processes, hormone levels, which leads to reduced consumption of feed by birds, and affects growth, egg production, and shell quality negatively. Insufficient nutrition also causes a lack of mineral elements and changes in the biochemical and morphological composition of the blood. The adaptation process in new climatic conditions is associated with a decrease in immunity, energy availability for cells, changes in the digestibility and metabolism of nutrients $[19,20]$.

The influence of both high and low temperatures on chickens leads to the activation of several physiological processes at once. These include changes in the acid-base status of the blood, changes in the level of thyroid hormones, an increase in the level of stress markers - corticosteroid hormones in blood plasma, and the ratio of heterophils to lymphocytes $(\mathrm{H}: \mathrm{L})$. The influence of high temperatures affects the structure and functions of the intestinal epithelium of chickens, the composition of the intestinal microbiota. In birds, a violation of the balance of lipid peroxidation and the antioxidant defense system is observed, which is reflected in an increase in the content of malondialdehyde and a decrease in the activity of glutathione peroxidase, catalase, and superoxide dismutase $[20,21,22]$. At the same time, animals need an increased intake of trace elements with antioxidant properties to neutralize the increased processes of lipid peroxidation. Many studies claim the importance of selenium, zinc, iodine, and antioxidant vitamins for the acclimatization of chickens and the positive impact of their additional sources $[23,24,25]$. Unfortunately, the biogeochemical conditions of the Lower Volga region do not make it possible to naturally compensate the bird's need for trace elements. The study of oxidative stress during acclimatization and adaptation to local conditions will be the objective of further research.

The high intensity of metabolic processes and demand to the mineral composition of the feed is typical for all productive breeds of chickens; the negative consequences of hypomicroelementosis can be observed not only in the Moscow black breed considered in this paper. Thus, the combination of new climatic features and the lack of important trace elements in the biogeocenoses of the Astrakhan Region make the adaptation process difficult for chickens imported from the Moscow Region. It is confirmed by the strong differences in hematological parameters in chickens in the studied groups. In the new conditions, chickens need methods of monitoring physiological functions that can detect violations that do not manifest themselves clinically.

\section{CONCLUSIONS}

The results of the analysis of hematological and biochemical blood parameters of chickens acclimatized in the Astrakhan Region significantly differ from those of chickens from the farm in the Moscow Region, who remained in their usual conditions of breeding and feeding. The comparison of the studied parameters in the two groups and with the indicators of physiological norms allows assuming with a significant degree of confidence that the birds have insufficient intake of nutrients and are in a state of stress.

The elemental composition of the blood also gives grounds to diagnose the development in new conditions of a latent form of combined I-and Se-hypomicroelementosis, probably causing a high intensity of lipid peroxidation in the body. At the same time, a drop in egg productivity by $19 \%$ is the recorded fact.

The use of drugs with selenium and iodine in a bioavailable form will contribute to better adaptation of chickens imported from other regions, increase resistance to stress factors, normalize metabolic processes, and reduce the level of oxidative stress as well due to increased activity of the enzymatic link of antioxidant protection.

\section{References}

[1] Q. Swennen, G. P. J. Janssens, S. Millet, G. Vansant, E. Decuypere, and J. Buyse "Effects of substitution between fat and protein on feed intake and its regulatory mechanisms in broiler chickens: Endocrine functioning and intermediary metabolism". Poultry Science, vol. 84, no. 7, pp. 1051-1057, 205.

[2] V. I. Vorobyev, D. V. Vorobyev, N. I. Zakharkina, A. P. Polkovnichenko, and V. A. Safonov. "Physiological status of 'king' squab pigeon (Columbia Livia gm. Cv. 'king') in biogeochemical conditions of low iodine, selenium and cobalt levels in the environment". Asia Life Sciences, vol. 28, no. 1, pp. 99-100, 2019.

[3] Yu. B. Salina, A. A. Utaliev, and S. O. Alexandrov "Agrochemical characteristics of the arable soils in the Astrakhan region". Agrochemical Bulletin, no. 5, pp. 2933, 2017.

[4] P. A. Polkovnichenko, A. P. Polkovnichenko, D. V. Vorobyev, and N. M. Soshnikov, "Microelement status of acclimatized guinea fowls as a diagnostic indicator of the latent form of hypomicroelementosis in the biogeochemical conditions of the Astrakhan region". Bulletin of the Michurinsky State Agrarian University, no. 4, pp. 160-163, 2018.

[5] N. O. Kharchuk, N. V. Stytsenko, K. Yu. Avdeikin, N. Yu. Karymova, A. S. Kostin, and D. V. Vorobyev, "Biogeochemical situation of Astrakhan and adjacent areas". In: Caspian International Youth Forum of AgroIndustrial Technologies and Food Security 2017. Collection of scientific articles, pp. 52-54, 2017.

[6] A. A. Svechnikova, "The influence of ecological factors on the concentration of selenium in the soil of the Astrakhan region". Problems of regional ecology and nature management. Natural sciences, no. 4(41), pp. 4345, 2012.

[7] P. F. Surai, "Selenium in poultry nutrition and health". Wageningen: Wageningen Academic Publishers, 2017.

[8] V. I. Vorobiov, D. V. Vorobiov, A. P. Polkovnichenko, P. A. Polkovnichenko, E. N. Shcherbakova, N. M. Soshnikov, N. I. Zakharkina, and K. S. Cherkashina, "Dynamics of microelements at quals and caesars in the 
biogeochemical conditions of Astrakhan region". Natural Sciences, no. 3(64), pp. 40-45, 2018.

[9] R. D. Miles, "Trace minerals and avian embryo development". Ciência Animal Brasileira, vol. 2, no. 1, pp. 1-10, 2001.

[10] K. Plemyashov, A. Aristov, S. Semenov, N. Kudinova, P. Aniphenko, G. Nikitin, A. Stekolnikov, and M. Ladanova, "Broiler chicken meat quality". Journal of Animal Science, vol. 97, no. S3, p. 294, 2019.

[11] V. Vorobyov, D. Vorobyov, P. Polkovnichenko, and V. Safonov, "Evaluation of hematological and metabolic parameters in small ruminants with trace element deficiency under different biogeochemical conditions". World's Veterinary Journal, vol. 9, no. 4, pp. 311-316, 2019.

[12] L. I. Kolmykova, and E. M. Korobova, "Iodine and selenium in natural waters as a risk factor in manifestation of endemic thyroid diseases (review)". Theoretical and Applied Ecology, no. 2, pp. 5-13, 2019.

[13] A. V. Vostroilov, I. Y. Ventsova, and V. A. Safonov, "Biochemical blood parameters and mineral metabolism in the adaptive period in the bovine cattle in the conditions of the Voronezh Region". International Journal of Biology and Biomedical Engineering, vol. 15, pp. 244248, 2021.

[14] N. S. Motuzko, Yu. I. Nikitin, V. K. Gusakov, V. F. Pinchuk, A. V. Sinkovets, E. N. Kudryavtseva, A. V. Ostrovsky, Zh. V. Vishnevets, and V. K. Matsvevich, "Physiological indicators of animals". Minsk: Technoperspektiva, 2008.

[15] I. V. Nasonov, N. V. Buiko, R. P. Lizun, V. E. Volykhina, N. V. Zakharik, and S. M. Yakubovsky, "Methodological recommendations on hematological and biochemical studies in chickens of modern crosses". Minsk, 2014.

[16] A. N. Barmin, M. V. Valov, N. S. Suvaev, and E. A. Kolchin, "Concerning global climate change: ninety-year trend of some climatic characteristics in the delta ecotones of the Caspian Sea region". In: IGCP Third Plenary Conference and Field Trip, Astrakhan, Russia, vol. 610, pp. 26-29, 2015.

[17] A. R. Ioshpa, and O. E. Kolomoychenko, "Assessment of climate unease in Astrakhan region". International Scientific Research Journal, vol. 12-1(54), pp. 84-86, 2015.

[18] A. F. Soleimani, I. Zulkifli, A. R. Omar and A. R. Raha, "Physiological responses of 3 chicken breeds to acute heat stress". Poultry Science, vol. 905, iss. 7, pp. 1435-1440, 2011.

[19] S. Yalcin, A. Collin, and P.B. Siegel, "Acclimatization of chickens to high and low temperatures". In 5. Mediterranean Poultry Summit of WPSA. 2016, October.

[20]A. Akbarian, J. Michiels, J. Degroote, M. Majdeddin, A. Golian, and S. De Smet, "Association between heat stress and oxidative stress in poultry; mitochondrial dysfunction and dietary interventions with phytochemicals". Journal of Animal Science and Biotechnology, vol. 7, no. 1, pp. 114, 2016.

[21] S. Yalcin, S. Özkan, M. Çabuk, and P. B. Siegel, "Criteria for evaluating husbandry practices to alleviate heat stress in broilers". J. Applied Poultry Research, vol. 12, pp. 382388, 2003.

[22]H. Lin, E. Decuypere, and J. Buyse, "Acute heat stress induces oxidative stress in broiler chickens". Comparative Biochemistry and Physiology: Molecular \& Integrative Physiology, vol. 144, pp. 11-17, 2006.

[23] S. S. Tawfeek, K. M. A. Hassanin, and I. M. I. Youssef, "The effect of dietary supplementation of some antioxidants on performance, oxidative stress, and blood parameters in broilers under natural summer conditions". Journal of World's Poultry Research, vol. 4, no. 1, pp. 1019, 2014.

[24]H. Echeverry, A. Yitbarek, P. Munyaka, M. Alizadeh, A. Cleaver, G. Camelo-Jaimes, P. Wang, K. O, and J. C. Rodriguez-Lecompte, "Organic trace mineral supplementation enhances local and systemic innate immune responses and modulates oxidative stress in broiler chickens". Poultry Science, vol. 95, no. 3, pp. 518527, 2016.

[25]Z. Song, Y. Guo, and J. Yuan, "Effects of dietary iodine and selenium on the activities of blood lymphocytes in laying hens". Asian-Australasian Journal of Animal Sciences, vol. 19, no. 5, pp. 713-719, 2016.

\section{Creative Commons Attribution License 4.0 (Attribution 4.0 International , CC BY 4.0)}

This article is published under the terms of the Creative Commons Attribution License 4.0

https://creativecommons.org/licenses/by/4.0/deed.en US 